\title{
ANTONIO MACEO Y EL LEGADO CUBANO EN MANSIÓN DE NICOYA, GUANACASTE, EN EL PAISAJE Y LA ORALIDAD LOCAL
}

\author{
ANTONIO MACEO AND THE CUBAN LEGACY IN MANSION DE \\ NICOYA, GUANACASTE, IN THE LANDSCAPE AND LOCAL ORALITY
}

Esteban Barboza-Núñez ${ }^{1}$

\begin{tabular}{|l|l}
\hline Recibido: 24.03 .19 & Aprobado: 03.08.19
\end{tabular}

DOI: $10.15517 /$ isucr.v20i42.41846

\section{Resumen}

A través de entrevistas de profundidad, el presente artículo indaga acerca del legado de Antonio Maceo y la colonia cubana en Mansión de Nicoya, Guanacaste, por medio de la percepción de los recuerdos del paisaje de mediados del siglo XX en la memoria de cinco entrevistados. El artículo utiliza el concepto de paisaje como una forma de ver y de percibir el entorno, así como jeroglífico social, a través del cual es posible denotar y analizar relaciones sociales y económicas en un determinado lugar. En el análisis de las entrevistas, se determinan tres derivaciones por medio del análisis de la idea del paisaje en los entrevistados: la presencia del legado de la figura de Maceo y de la colonia cubana como fuente de identidad comunal, Mansión como uno de los centros logísticos más importantes de la Guanacaste de la mitad del siglo XX, y Mansión como centro de rica producción agrícola para el mercado regional y nacional.

Palabras clave: Paisaje; paisaje cultural; historia; Cuba; Costa Rica.

\begin{abstract}
Through in-depth interviews, this article explores the legacy of Antonio Maceo and the Cuban colony at Mansion de Nicoya, Guanacaste, through the perception of the reminiscences of the midtwentieth century landscape in the memory of five interviewees. The article uses the concept of landscape as a way of seeing and perceiving the environment, as well as a social hieroglyph, through which it is possible to denote and analyze social and economic relations in a specific place. In the analysis of the interviews, three derivations are determined by means of the analysis of the idea of landscape in the interviewees. The first one is the presence of the legacy of the figure of Maceo and the Cuban colony as a source of communal identity, the second one deals with Mansion
\end{abstract}

\footnotetext{
${ }^{1}$ Costarricense, professor catedrático, Universidad Nacional, Sede Regional Chorotega, Campus Nicoya. Email:
} esteban.barboza.nunez@una.cr 
as one of the hubs in Guanacaste in the mid-twentieth century, and finally, Mansion as a center of rich agricultural production for the local and national markets.

Keywords: landscape; cultural landscapes; history; Cuba; Costa Rica

\section{Introducción}

A través del uso de entrevistas de profundidad, y con el paisaje como una forma de ver que expresa significado y que constituye una extensión de ciertos ideales de quienes lo producen (Mitchell, 2009); además de la historia local, entendida como el estudio del pasado a partir de una delimitación temporal y espacial bastante específica (Serrano, 2009), este trabajo pretende abordar parte del legado de Antonio Maceo y la colonia cubana en Mansión de Nicoya, Guanacaste, tanto en aspectos relacionados con la forma de recordar el entorno, como con su relación con identidades y subjetividades contemporáneas. ${ }^{2}$ Esta noción de paisaje, además de las particularidades locales, diferenciadas de colectividades mayores como los imaginarios nacionales o incluso regionales -en el caso de la provincia de Guanacaste-, pueden arrojar nuevos matices que anteriormente hayan podido pasar desapercibidos en intentos previos de esbozar el legado y la percepción de la colonia cubana y de Antonio Maceo en la comunidad de Mansión, a partir de su establecimiento en ese lugar en 1891.

Metodológicamente hablando se propone que, a través de entrevistas de profundidad a adultos mayores con un fuerte arraigo en Mansión, estos se puedan referir principalmente a dos elementos: en primera instancia, Antonio Maceo y la colonia cubana como legado identitario de este distrito nicoyano; y, por otra parte, a la memoria del paisaje ancestral de Mansión y los elementos extraídos a partir de imágenes visuales que puedan ligarse al desarrollo de la comunidad como reflejo del emprendimiento de Maceo, además del posterior devenir de esta, una vez que una parte de los colonos cubanos regresara a Cuba y la otra se estableciera en esa comunidad definitivamente, y dejara descendencia trazable hasta el día de hoy.

\footnotetext{
${ }^{2}$ Antonio Maceo Grajales es una figura fundamental en la independencia cubana. Junto a José Martí y a Máximo Gómez constituye uno de los baluartes de la gesta independentista contra los españoles, principalmente en la Guerra de los Diez Años (1868-1878) y la Guerra del 95 (1895-1898). A través del contrato Lizano-Maceo, durante la administración de José Joaquín Rodríguez, Maceo estableció una colonia agrícola en Nicoya, con colonos cubanos, y permaneció en el país de 1891 a 1895, cuando regresó a Cuba, en donde moriría en combate el 7 de diciembre de 1896.
} 
Una vez se recolecten los datos, se procederá a su análisis tomando en cuenta dos premisas específicas. La primera tiene que ver con el paisaje, que será conceptualizado como un elemento que expresa significado, además de ser una forma de ver. Conjuntamente, en un sentido marxista, como se explicará más adelante, el paisaje tendrá una categoría de jeroglífico social, que enuncia articulaciones de poder, formas de conceptualizar la riqueza, y las relaciones sociales entre miembros de una comunidad, en el caso de este trabajo, Mansión. La segunda premisa es el concepto de historia local, sumamente útil a la hora de explorar particularidades históricas con mayor delimitación de tiempo y espacio que, por ejemplo, las de las narrativas históricas nacionales, o incluso regionales, en una provincia como Guanacaste, extensa y con una historia y composición étnica y cultural variada, en la que, sin embargo, predomina la hacienda ganadera como principal motor de identidad y cohesión social desde los tiempos de la colonia, y que tiende a dejar de lado particularidades como las que presenta Mansión.

Trabajos anteriores, como los de Juan José Marín y Rodolfo Núñez (2016), Carlos Arauz (2012), o Esteban Barboza (2014), ya han tratado algunas particularidades específicas de la estancia de Maceo en Costa Rica desde una configuración regional. Incluso, desde una perspectiva metodológica, esos trabajos podrían apuntar a la historiografía local, o micro historia, principalmente en el caso de Marín y Núñez. Estos y otros autores han recurrido a entrevistas con habitantes locales de diversas edades con el fin de indagar acerca de su conocimiento y relación con Maceo y la colonia cubana; en torno a la contextualización del general cubano dentro del contexto guanacasteco de finales del decimonónico; han elaborado mapas mentales, con ayuda de informantes, de entornos de inicios del siglo XX en Mansión; y han explorado las formas y razones por las que se recuerda y olvida ciertos elementos relacionados con Maceo. Sin embargo, temas específicos, como la reelaboración y resemantización de paisajes que ya no existen, y cómo esas reelaboraciones pueden dotar de elementos diferenciadores de discursos históricos a nivel provincial o nacional a una comunidad como Mansión, son temas aún no discutidos y que se pretenden tratar en este espacio.

La producción académica en revistas y libros editados en Costa Rica sobre Maceo más bien ha tendido a abordar aspectos ordinarios de su estancia en el país, acaecida entre 1891 y 1895 . Desde el seminal artículo de Herminio Portell Villa, aparecido en la revista Repertorio Americano (1948), acerca de la amistad del general cubano con el escritor Manuel González Zeledón, o el texto pionero 
de Ulises Delgado, Maceo en Costa Rica (1969), hasta trabajos más recientes como el Idearium Maceísta (2001), de Armando Vargas Araya, Costa Rica en Antonio Maceo (2016), de Antonio Álvarez y Esteban Barboza, o bien artículos como "Con ternura de hijo quiere el cubano bueno a Costa Rica” (2017) de Edelmis Reyes y Alberto Matos-Guerra, e incluso en trabajos de ficción como la novela El año del laberinto (2010), de Tatiana Lobo -en el que Maceo es un personaje secundario-, se ha recurrido a esbozar aspectos, si bien sumamente importantes y reveladores, de índole tendiente más bien a lo general. Entre estos aspectos se puede citar el contexto costarricense en el que se afincó Maceo; las particularidades del contrato Lizano-Maceo, que daría pie al establecimiento de la colonia cubana en Nicoya; el estudio de fuentes primarias del siglo XIX, como periódicos o actas del Congreso, para entender mejor la recepción que tuvo Maceo en San José y en Guanacaste; así como ciertos pormenores de la zona rescatados de narraciones de viajeros o periódicos locales. Sin embargo, el paisaje como concepto que pueda ayudar a reconstruir espacios que alguna vez existieron, y con fuentes orales locales como medio de reconstrucción, no ha sido tratado con detalle hasta ahora.

La historia local como contraparte a la historia hegemónica positivista: su pertinencia en el contexto guanacasteco

Una pregunta fundamental acerca de los modos de adquirir conocimiento antropológico es la que formula el antropólogo estadounidense Clifford Geertz (1994). Geertz elabora acerca de la manera de crear ese tipo de saber a partir del modo en que piensan, sienten y perciben los nativos entrevistados o estudiados. En este caso, utiliza el vocablo nativo, según aclara, "en el sentido estricto del término" (p. 74). Ante tal cuestión, sostiene que lo que realmente existe es un problema epistemológico, en cuanto a la capacidad o no de un antropólogo de identificarse con un informante, y, a la vez, mantener su "objetividad científica" acerca de la metodología con que se recopila e interpreta la información.

Como solución, Geertz propone adaptar las tesis del psicoanalista Heinz Kohut (1977) y sus conceptos de "experiencia próxima" y "experiencia distante". El primer caso se refiere a una experiencia y capacidad que alguien, por ejemplo, un informante, tiene para poder emplear naturalmente y sin esfuerzo algunos medios que definan lo que este y sus prójimos ven, sienten, o imaginan. Por otro lado, la experiencia distante será aquella que un especialista emplea para 
impulsar sus propósitos científicos, filosóficos, o prácticos. Es decir, para Geertz la solución a su pregunta no está en imponer, desde la ciencia y el conocimiento hegemónico, categorías que los informantes deberán asumir. Más bien se trata de descifrar qué cree el informante ser a través de una identificación transcultural del etnógrafo con este.

Sin pretender establecer correspondencias exactas, sino aproximaciones que puedan contribuir a entender más adecuadamente el papel que le podríamos asignar, en un trabajo como este, a la historiografía local, esta vendría a ser esa manera de poder interpretar el pasado de ciertos sujetos en contraposición con la historiografía hegemónica y positivista, que ha tendido más bien a aglutinar y homogenizar, para propósitos específicos, diferentes pueblos, saberes y formas de pensar bajo una misma sombrilla, a menudo nacionalista, y que enmascara poderes e intereses hegemónicos de los grupos de poder. En este sentido, la narrativa histórica costarricense, la filosofía, y la literatura desde finales del siglo XIX y gran parte del XX, han estado influenciadas enormemente por ese interés de cohesión homogéneo de índole nacionalista, modelado según los intereses de las clases dominantes.

Esta influencia ha abarcado aspectos que van desde la formación de una conciencia nacional costarricense, en la segunda mitad del siglo XIX, con gran contribución del pensamiento liberal, hasta la consolidación de la identidad nacional, a finales de ese mismo siglo. Trabajos como los de Iván Molina (2002), Alexander Jiménez (2005), Álvaro Quesada (1995), o Carlos Cortés (2003), en disciplinas como la historia, la filosofía o la crítica literaria, son referentes fundamentales para entender estos procesos, y cómo los discursos hegemónicos han permeado de arriba a abajo los procesos identitarios nacionales, hasta el punto de invisibilizar o discriminar abiertamente todo lo que no calce con las ficciones fundacionales de las clases dominantes del Valle Central costarricense y su noción de nación.

Estas generalizaciones, y los motivos e intereses detrás de aglutinamientos de este tipo, principalmente producidos y divulgados por lo que Antonio Gramsci (1971) llamó intelectuales orgánicos -esos sujetos que de alguna u otra forma pueden convertirse en instrumentos de los intereses de las clases dominantes y en divulgadores de sus ideales a través de su producción intelectual-, han tendido a opacar otras versiones del pasado, ya sea desde una perspectiva de clases, o desde periferias regionales y económicas como Guanacaste, en donde, hasta mediados del siglo $\mathrm{XX}$, predominó la unidad de producción de la hacienda ganadera como principal articulador social. 
Este modelo, introducido en la región en 1561, cuando Juan de Cavallón implanta los primeros hatos de ganado traídos desde Nicaragua (Sequeira, 1985), llegó a concentrar grandes cantidades de terreno en pocas manos, con una escasa inversión de capital, y con modos de vida que generarían grandes exclusiones sociales. Se posicionaba al hacendado en la cima de la escala social, y los peones, sabaneros y precaristas se disputaban y repartían las cuotas de poder restantes, en cercanía o lejanía con los grupos hegemónicos, como bien lo ha documentado Marc Edelman (1998).

Los intereses, por un lado, de los hacendados guanacastecos, de mantener su hegemonía en la región, y los de la oligarquía cafetalera del Valle Central de definir los modos de constitución de la nación, por el otro, hicieron que en la discursiva oficial otras formas de convivencia y otras unidades de producción se vieran menoscabadas en la narrativa nacionalista costarricense. Tanto a nivel guanacasteco, según Barboza (2014b), como a nivel nacional, de acuerdo con Marín y Núñez (2016), emprendimientos como el de Maceo se verían opacados por imaginarios que enfatizarían el legado cultural de la gran hacienda ganadera, en el primer caso; y en el segundo, por el del ambiente anti cubano que reinó en el discurso oficial del Estado costarricense después del triunfo de la revolución liderada por Fidel Castro en 1959.

En este panorama surge la colonia cubana de Maceo en Nicoya, con una visión liberal radical, con enormes diferencias en cuanto a la idea de la distribución de la tierra, la explotación de los recursos naturales, el uso del suelo, la educación, y las unidades de producción propuestas, con respecto al modelo de la hacienda ganadera en Guanacaste. Para el estudio y la interpretación de estas propuestas, la historia local puede proveer alternativas útiles e interesantes, a menudo eclipsadas en la historiografía nacional costarricense, en la regional guanacasteca, e incluso en la visión cubana de la estancia de Maceo en Costa Rica, que tiende a ser vista solamente como un preparativo para su incursión armada en Cuba contra los españoles.

Como apuntan estudiosos del concepto de historia local, entre ellos Prado Arellano (2006), es precisamente función de esta estudiar y hacer visible todo aquello que no necesariamente sea historiable, en el sentido que ayude a demostrar los mitos fundacionales del Estado y la Nación. En el caso de Maceo, a pesar de que su estancia en Nicoya no sea necesariamente vista como un acontecimiento de primera importancia en la historia oficial costarricense, o en la cubana, el impacto de su empresa en los habitantes locales de Mansión, aún bien entrado el siglo XXI, no deja de proveer sentido a la identidad regional de esa comunidad, o incluso a la de Nicoya, al tiempo 
que les permite a sus habitantes reconocerse a sí mismos a través del legado de sus antepasados o vecinos cubanos.

Entonces, y según afirma Francisco Zuluaga (2006), la historia local, en su práctica, debe cobijar varias maneras de reflexionar un hecho o acontecimiento, y dar lugar, a la vez, para que quepan "tanto los movimientos colectivos como las acciones individuales, y tanto las tendencias como los acontecimientos" (p. 2). De hecho, Peter Burke, en su ensayo sobre formas de hacer historia (1996), afirma que las historias nacionales, predominantes en el siglo XIX, deben ser cuestionadas y tienen que competir con la historia local, anteriormente desdeñada por los historiadores profesionales y delegada a aficionados o a anticuarios. Es importante, eso sí, tener en cuenta que estas historias son dinámicas y están sujetas a ser influenciadas, ciertamente, por discursos hegemónicos, y por aspectos macroeconómicos y culturales de índole nacional. Es decir, no podemos afirmar que existan totalmente aisladas de sus contextos macro.

El paisaje como alegoría ideológica

En el ámbito académico término paisaje suele ser, irónicamente debido a su cotidianidad y a su naturaleza polisémica, más problemático de lo que aparenta. Distintas áreas del saber, como la geografía, la pintura, la filosofía o la literatura tienden a darle distintos usos a este vocablo y, por ende, a definirlo de formas distintas. En una definición de índole amplia, se podría decir que el paisaje tiene que ver con la comprensión de un lugar, o un elemento particular de este a través de apreciaciones sensoriales acerca de una realidad específica (Castillo, 2016). Según la disciplina que lo aborde, su dimensión fluctúa entre una realidad física, un ente cultural relacionado con el desarrollo de las sociedades, como un bien perceptible en una determinada sociedad, y como una forma de ver influenciada por la subjetividad del observador (Zubelzu y Allende, 2015).

En cuanto a esta última cualidad del paisaje, es decir, el mismo como una forma de ver, es importante la contribución W.J.T. Mitchell (2002), quien aclara que, en su aproximación al paisaje, su objetivo principal es cambiar la palabra "paisaje" de un sustantivo a un verbo. Es decir, propone que se debería pasar de usar el vocablo para encasillar un objeto o un texto, a analizar y explicar cómo el proceso de ver contribuye a formar identidades sociales y subjetivas. En ese sentido, el autor favorece un enfoque que trate al paisaje como alegoría de temas psicológicos e ideológicos. 
Entonces, si el paisaje es una forma de ver, no es el espacio o el lugar por sí mismo lo que existe, sino lo que logra aparecer, en el caso de una pintura o una fotografía, dentro del cuadro; y en el caso de la narración de un paisaje, lo que se decide incluir y narrar. Esto implica, consecuentemente, la decisión, consciente o inconsciente, de quien enmarca, de contener o dejar por fuera ciertos elementos. Lo contenido y lo excluido servirán para denotar los ideales y la visión de mundo de quien está produciendo el paisaje. De ahí la importancia de entender que el paisaje es una forma de ver que expresa significado, como se acotó al principio de este trabajo, y no simplemente algo que está ahí y puede ser cognoscible por sí mismo, cuya imposibilidad ya la ha advertido Kant, quien afirma que un objeto no es inteligible por sí mismo, sino a través de la carga subjetiva proyectada por el observador (Kant, 1977).

Desde la aparición del paisaje en la pintura europea, desde finales de la Edad Media y comienzos del Renacimiento, este comienza a funcionar como una forma de expresar significado. A través de las posibilidades y limitaciones que otorgaban el marco y el fondo de un paisaje, pintores como Ambragio Lorenzetti, o Johan Limbourg, en los siglos XIV y XV, comezaron a utilizar el paisaje como algo más que un detalle decorativo del cuadro, y más bien mostraban modos de vida, unidades de producción, concepciones de riqueza, convivencia, comercio o agricultura a través de este.

Incluso durante la conquista de América, y posterior a esta, como apunta Peter Sloterdijk (2007), el "descubrimiento", el nombramiento y el registro de espacios y paisajes fue fundamental para la posterior apropiación y puesta en marcha de empresas colonialistas y capitalistas en el continente americano. En este caso, se utilizó el paisaje para expresar valor, riqueza y necesidad de conquista a través de modos de ver que reflejaban las ideas que los exploradores europeos tenían con antelación acerca de lo que buscaban en el continente americano.

De este modo, el paisaje se convierte en un jeroglífico social que señala todo tipo de relaciones que abarcan planos económicos, concepciones de mundo, e ideales de la sociedad que produce lo produce. Por jeroglífico social, entendemos lo que Karl Marx estipula en cuanto al valor de una mercancía, devenida del trabajo humano, que transforma todo producto de trabajo, que penetra el secreto del producto social, de sus objetivos y de sus efectos (Marx, 2007). El poder interpretar ese producto conduce al acceso a los detalles de esas relaciones de poder, de las 
ideologías proyectadas en él, y a las consecuencias en los actores que aparecen enmarcados en ese paisaje.

Modos de vida, reinvindicación de lo local y la herencia de Maceo en el paisaje de Mansión: tres posibles derivaciones

Como se apuntó al inicio de este trabajo, la entrevista de profundidad a adultos mayores nativos de Mansión es el instrumento principal, en el ámbito de este escrito, para recabar información acerca de la constitución de su comunidad y la herencia de Maceo a través del paisaje de mediados del siglo XX, tal y como ellos lo recuerdan. En conversaciones libres se introdujo preguntas acerca de los recuerdos más antiguos que tenían del entorno de Mansión; acerca de la economía de la comunidad, a nivel comercial y agrícola, y a nivel familiar y personal; en torno a la relación de Mansión con los paisajes aledaños y la distribución de los comercios y las casas en el centro del poblado; en cuanto a las formas de recreación de los habitantes locales, niños y adultos; acerca del nivel de desarrollo comercial, de servicios, transporte, e infraestructura en comparación con comunidades vecinas como Nicoya, Hojancha o Carmona; en cuanto a los cultivos, unidades de producción y formas de distribución y consumo de bienes; en torno al legado visible de Maceo y la colonia cubana en el paisaje de la niñez de los sujetos entrevistados; en cuanto a la conciencia del legado de Maceo en la formación y el devenir de la comunidad; y las comparaciones entre la Mansión actual y la de la niñez de los entrevistados. Se trató de que todos estos elementos fueran recordados y recabados por medio de imágenes mentales que se aproximaran a paisajes.

Por las edades de los informantes, que rondan entre los 65 y los 85 años, evidentemente los paisajes recordados y recreados son de mediados del siglo $\mathrm{XX}$, en un espacio de tiempo que ronda entre las décadas de los cuarenta, cincuenta e inicios de los sesenta de esa centuria. La exactitud de las fechas es imprecisa, ya que los entrevistados, en la gran mayoría de los hechos acotados, no recuerdan los años específicos en que las imágenes y los hechos que recuerdan se dieron, por lo que se trabaja con aproximaciones. Esto, por el tipo de entrevista y por el tipo de enfoque, que es cualitativo, no supone un problema mayor, ya que, como se acotó anteriormente, se favorece la autopercepción del informante y su propia visión del entorno, siempre en un lenguaje y en modos de expresarse que le sean familiares. 
A través de las entrevistas de profundidad realizadas a cinco sujetos nativos de Mansión, nacidos entre 1934 y 1954, y con un fuerte arraigo en esa comunidad, fue posible establecer tres derivaciones o visiones principales del poblado y de Maceo a través de la narración de los paisajes y los espacios que se recuerdan. La primera tiene que ver con el rastro, en la memoria paisajística, de la colonia cubana, su industria azucarera y el legado y el simbolismo de Maceo en la comunidad. La segunda tiene que ver con la posición de Mansión como un villorio pujante y que, básicamente, según los mismos informantes, aún a mediados del siglo XX funcionaba como un centro logístico en la península de Nicoya, y aún más interesante, como la puerta de entrada a Guanacaste, a través de Puerto Jesús, en el golfo de Nicoya, así como lugar de almacenamiento y distribución de la producción agrícola de la zona, según los recuerdos de los entrevistados. Finalmente tenemos el recuento de los paisajes aledaños a Mansión, como terrenos de mayor actividad productiva que en la actualidad, así como de mayor riqueza escénica y natural que en nuestros días, algo interesante para alguien que nunca vio esos paisajes y que, aún hoy en día, podría considerar a Mansión como de gran belleza escénica y pujante actividad agrícola.

El legado y el simbolismo de la figura de Antonio Maceo y la colonia cubana en la memoria del paisaje

En cuanto a la primera derivación, el actual parque Antonio Maceo en Mansión constituye, para los entrevistados, un espacio muy importante que se recuerda como parte del paisaje que conecta a la comunidad con el general cubano. Los hermanos Laureano y Pablo Ramos, nietos de Juan Pablo Ramos Fleita, uno de los patriotas cubanos que ayudó a fundar la colonia en la última década del siglo XIX, marcan la diferencia que, según sus memorias, existe hoy en día en ese espacio, con el busto de Maceo y la caldera del auntiguo ingenio de los cubanos, las bancas para sentarse, el patio de recreo para niños y la cancha de baloncesto actual, dentro del parque, con la forma en que se reverenciaba y se utilizaba el espacio a mediados del siglo $\mathrm{XX}$.

Según Pablo Ramos, en versión confirmada por su hermano, a mediados del siglo pasado "el parque estaba totalmente cerrado. No se podía entrar. Era un espacio para los cubanos. Había un señor limpiando todo el tiempo. No dejaban entrar a nadie, solamente cuando llegaban los cubanos a la escuela, entonces los llevaban allá, abrían el portón. Entonces se podía entrar” (Ramos, 2018). El espacio que ocupa el actual parque, cuidado en esa época con gran esmero, según los 
informantes, funcionaba entonces como una suerte de patrimonio que recordaba la figura de Maceo en la comunidad. Según Carlos Arauz Ramos (2018), otro entrevistado, y también descendiente de cubanos, su abuelo, Juan Pablo Ramos Fleita, el mismo de los hermanos Ramos, tenía un negocio frente al actual parque. En dicha tienda, aún a finales de los años cincuenta del siglo XX, ondeaba la bandera cubana, y desde ese lugar, afirma Arauz, su abuelo custodiaba el parque, con el fin de que en ese espacio se conmemorara la figura y la memoria de Maceo con el mayor de los respetos.

Aunque nunca llegó a ser considerado patrimonio desde el punto de vista formal, queda claro que, según la narración de los hermanos Ramos y de Arauz, el sentido que se le daba al lugar, cerrado con verjas y dedicado exclusivamente a la memoria de Maceo -y no al lugar de recreo que es hoy- aproximan el espacio referido a una especie de patrimonio que, incluso, se podría argumentar, cumplía con algunos de los parámetros actuales de la UNESCO en cuanto a la definición del mismo. Es decir, el espacio cerrado y cuidado con esmero funcionaba como un emblema que transmitía cierta memoria a la colectividad y a las generaciones presentes y futuras (UNESCO, 2014).

Además, según la definición fenomenológica de patrimio (Dormaels, 2011), en la que este se entiende como el resultado de una significación simbólica en la que se construyen nuevos valores de uso, y en donde el monumento en sí -en este caso, el espacio cerrado dedicado a Maceo- no constituye el patrimonio como tal, sino lo que se recuerda, el espacio narrado por los hermanos Ramos y por Arauz parece cumplir esas específicaciones. Conmemoraba a Maceo y a los cubanos fundadores del pueblo. El espacio actual, aunque conserva el busto y la caldera del antiguo ingenio, parece haber perdido bastante esa función que apuntan los entrevistados. Varios de los elementos que lo componen actualmente poca o ninguna relación tienen con Maceo. El espacio cerrado y custodiado de mediados del siglo pasado, con una clara conexión con Maceo y Cuba, denota, indudablemente, parte del legado de los colonos cubanos, bien recordado por los entrevistados.

El parque en sí se estableció como tal en 1951, cuando se colocó la primera piedra (Delgado, 1969), por iniciativa local y con apoyo municipal. Además, fue el centro, principalmente durante la década de los años cincuenta, de considerable actividad diplomática por parte de los delegados cubanos en Costa Rica, algo que confirma por medio de entrevista para este trabajo Rubaldo Batista (2018), nieto de Pedro Batista, uno de los colonos cubanos que llegaría con Maceo. Batista afirma 
que de joven ganó una beca otorgada por Rosendo Canto Hernández, en esa época embajador del gobierno de Fulgencio Batista en San José, para estudiar en Cuba una carrera universitaria, a raíz de la visita de diplomáticos cubanos a Mansión. Ese proyecto, sin embargo, se vio truncado por la oposición de sus padres ante la larga ausencia de Guanacaste que supondría, para el joven Batista, estudiar en Cuba; y, más adelante, por el triunfo de la revolución liderada por Fidel Castro, en 1959, y que significó el relevo de todo el cuerpo diplomático destacado en el país, así como el distanciamiento entre ambos países en los años posteriores.

Otra obra arquitectónica importante que, como parte del paisaje, recuerda directamente a los cubanos, es la que los entrevistados llaman "la cárcel”. Esta, aunque no funcionara realmente como una cárcel, sino como una celda, representa un espacio descrito por los entrevistados como "sólido, de cemento, y que aún está en pie" (Ramos, 2018b), y que, según afirman, era parte del complejo habitacional e industrial que construyeron los cubanos. El espacio es sifnificativo en cuanto a que se describe como fuerte, macizo y duradero; y, a partir de las decripciones de los entrevistados, se puede asociar simbólicamente con la perdurabilidad del legado de Maceo. En una época en que las construcciones eran principalmente de madera, y en su gran mayoría ya no están en pie, el tener un edificio de cemento, que recuerde directamente a los cubanos, en especial en el imaginario de quienes eran niños a mediados del siglo $\mathrm{XX}$, es sumamente significativo, independientemente de si el edificio al que se refieren los entrevistados estuviera directamente ligado a Maceo o incluso a la colonia cubana. Es un elemento palpable y tangible que todo adulto mayor del pueblo asocia directamente con Maceo. La perdurabilidad del mismo se entremezcla con el de la memoria de la construcción del ingenio, de la colonia, y del mismo Maceo.

En cuanto a lo que evoca la imagen y el nombre de Maceo entre los entrevistados, se notó que se le recuerda como "un gran luchador", al tiempo que reconocen que en su infancia se les enseñó a admirarlo y a respetarlo mucho, aunque en su mayoría no sepan detalles acerca de la vida del general antes de la fundación de Mansión, o su significado para la nación cubana. Términos como "gran hombre", "luchador", "disciplinado", "de buen corazón”, se tienden a usar, por los entrevistados, más bien en un sentido metafórico, y en alusión al esfuerzo que conllevó la fundación de la colonia y la introducción de la maquinaria utilizada para el ingenio azucarero construido por los cubanos, en una época en que las carreteras, tal y como las conocemos hoy en día, no existían. Esta visión es interesante en cuanto a que difiere bastante de la imagen canónica de Maceo, como 
hombre de guerra, como un hábil estratega militar, y como uno de los baluartes de la independencia cubana. Al mismo tiempo, le otorga al general un significado nuevo y sugerente, como pionero, empresario, emprendedor y fundador del que llegaría a ser, aún a mediados del siglo XX, uno de los centros poblacionales más importantes de Guanacaste, con una abundante vida comercial y social.

Siguiendo dentro de la primera derivación, acerca de Maceo y el legado cubano en Mansión, cabe resaltar el énfasis que hacen los entrevistados en las diferencias culturales entre los colonos cubanos y sus descendientes, por un lado, y la cultura y la idiosincrasia guanacasteca de la época, por el otro. Se enfatiza el contraste entre la ganadería de zonas como Nicoya y los pueblos cercanos al río Tempisque, como Pozo de Agua o Quebrada Honda, y la mayor diversidad agrícola de Mansión; así como la mayor conservación del bosque a sus alrededores, a diferencia de Nicoya, donde este había desaparecido antes y en mayor medida, como consecuencia de la explotación ganadera. Según Carlos Arauz (2018), los descendientes de los cubanos, y en general, los habitantes de Mansión tendían a preservar más el bosque y a explotar el espacio de maneras menos invasivas que las generadas por el aprovechamiento ganadero, al tiempo que estos modos de explotación resultaban más beneficiosos, tanto a la hora de proveer subsistencia propia, como a la hora de producir y vender productos agrícolas, ya fuera en Nicoya o en Puntarenas. Rubaldo Batista, una generación mayor que Arauz, afirma lo mismo, cuando expresa que "los cubanos respetaron más el bosque que los guanacastecos” (Batista, 2018).

Arauz traza las diferencias culturales que existían entre los habitantes de Hojancha o Nandayure, que trataban de "transplantar", según afirma, sus villorios originales del Valle Central a esos territorios, siempre con gran laboriosidad y dedicación; los habitantes de Mansión, también muy trabajadores y con un gran sentido del desarrollo y el progreso heredados, afirma, de los colonos cubanos; y, finalmente, los nicoyanos, más pasivos y menos laboriosos, y con mayor dependencia de la ganadería para subsistir. Según Arauz, "los cubanos eran muy dedicados a la agricultura y el nicoyano no tanto. El nicoyano era más dedicado a la ganadería, de lo que es Nicoya para allá, como para Pozo de Agua, y todas esas partes. Los cubanos no tenían la mentalidad de hacer corrales" (Arauz, 2018).

Este tipo de relación con la tierra, posicionaba a Mansión no solo como una comunidad productora; también era vista como un lugar de comerciantes: "se sacaban [los productos agrícolas] 
a Puntarenas, algunos sí los llevaban a Nicoya, llevaban a vender pipianes, chayotes, frijoles, maíz y digamos, al otro núcleo de otras zonas que eran más costeras, que se dedicaban a la pesca, y al pescado seco" (Arauz, 2018). Rubaldo Batista coincide con Arauz, y confirma que se producía muchos granos básicos, especialmente frijoles y maíz (Batista, 2018). Es decir, no solo se ve en las entrevistas a Mansión como puerta de entrada a Guanacaste; también como un lugar desde el cual, y en parte debido a la influencia de la mentalidad agrícola que traían los cubanos, y más tarde, la de los migrantes del Valle Central, se suplía de alimentos a las poblaciones vecinas, especialmente a las ganaderas, con menos inclinación hacia la agricultura.

Es interesante que Arauz le da un aire bucólico a los modos en que los habitantes de Mansión se relacionaban con el medio ambiente. Cultivavan su propia comida, afirma, pescaban en el río Morote peces y camarones para su consumo propio. También cazaban en los montes aledaños que aún conservaban la cobertura boscosa, en un universo y en un paisaje descrito de forma idílica y nostálgica, en el que se entremezcla el uso del río y de la tierra con recuerdos del seno familiar. De este modo, el paisaje y las unidades de producción del poblado se combinan con las experiencias personales de los informantes, como sus excursiones a las pozas del río Morote a nadar, o a pescar camarones con los cubanos en las noches oscuras, y luego organizar, a partir de las once de la noche el festín de comerlos, con toda la actividad social que eso conlleva.

Es precisamente en el plano íntimo y familiar donde estas diferencias eran más marcadas. Aún a finales de los años cincuenta e inicios de los sesenta del siglo XX, según afirma Arauz, era posible distiguir los contrastes, a nivel íntimo, entre las familias de ascendencia cubana y las familias sin ascendencia cubana. Las reuniones familiares eran frecuentes en torno a parientes mayores llegados de Cuba, o bien sus hijos. Parte de lo que se celebraba en esas reuniones, afirma el entrevistado, era la idiosincracia y la cultura cubana; y de niño, afirma haber reconocido diferencias entre esta cultura y la nicoyana: "todos los fines de semana visitábanos la casa de mi abuelo, se organizaban comidas, se mataba un chancho a menudo, pescábamos camarones, y se notaba el carácter alegre de los cubanos, aunque a veces podían ser muy reflexivos y comedidos" (Arauz, 2018).

Si bien es cierto, las reuniones de las familias extendidas son comunes también en la cultura costarricense, y en casi cualquier cultura alrededor del mundo, es importante notar la relación que establece el entrevistado entre las reuniones familiares y la cultura cubana. De alguna forma, estos 
eventos, se puede afirmar, funcionaban como vehículos de cohesión social alrededor de una identidad propia, aunque fuera en el seno familiar, aldededor de figuras que estaban ligadas directamente a la fundación del pueblo y con el legado cubano en la comunidad. El mismo informante afirma que se "mantenían ellos con esa cubanidad, se sentían cubanos. Mantenían su identidad, las costumbres y comidas, que eran muy cubanas. Cada cierto tiempo se reunían con mi abuelo" (Arauz, 2018). Este tipo de actividades, además de la función del parque, demuestran, según lo acotado por los entrevistados, que la identidad cubana en Mansión se mantenía vigente a mediados del siglo pasado.

Mansión como centro logístico de la península de Nicoya en el relato del paisaje

En cuanto a la segunda derivación de las entrevitas y lo que los consultados recuerdan de Mansión desde la perspectiva económica y social, el poblado es rememorado como una comunidad pujante, con más actividad comercial y social que en la actualidad. La escuela Antonio Maceo, de la que uno de los informantes, Rubaldo Batista, llegó a ser profesor, tenía, a mediados del siglo XX, alrededor de 400 estudiantes, y Batista afirma haber sido uno de 17 docentes que conformaban la planilla del centro educativo, a finales de los años cincuenta e inicios de los sesenta. En todas las entrevistas sobresale un énfasis en el comercio y la vitalidad del lugar, ya sea como zona de paso; como puerta de entrada a Guanacaste, desde Puerto Jesús; como espacio de almacenamiento de productos locales; como centro de transporte de esos productos a Nicoya o Puntarenas; como un poblado que fue capaz de albergar tiendas de abarrotes, de ropa, carnicerías, y hasta cine; como una aldea que tenía un desarrollo económico mayor al de otros pueblos aledaños que más tarde gozarían del título de cantón; o como centro social entre poblaciones aledañas.

Carlos Arauz afirma que Mansión, gracias al emprendimiento cubano de finales del siglo XIX, específicamente a causa del ingenio establecido por Maceo, fue el primer poblado de la península en contar con electricidad y alumbrado público, mucho antes que Nicoya. Sin embargo, como bien advierte Rubaldo Batista, esa electricidad no era pública, y solo la podía tener quien la pudiera comprar directamente al productor, una práctica habitual antes de la creación del Instituto Costarricense de Electricidad, en 1949, y que significó la nacionalización de la producción eléctrica en el país. 
Los entrevistados, además de Arauz, a partir de ese carácter emprendedor de Maceo, concuerdan en que, durante su niñez, el centro del pueblo era más pujante que ahora. Según Laureano Ramos (2018), a mediados del siglo XX, "había como cuatro o cinco tiendas. Había un bus cada media hora para Puerto Jesús. Y era un mercado eso. Había cine, carnicerías. De todo había ahí. Y la gente llegaba de todos lados ahí. Daba la impresión de que iba a ser más grande que Nicoya". Otros entrevistados confirman la visión del primer consultado, y afirman que, de todos los pueblos aledaños, como Matina, Hojancha y Guastomatal, venían personas a vender sus productos y a comprar enseres básicos en las tiendas del pueblo. Incluso, el entrevistado más longevo, Rubaldo Batista, relata cómo en los años cuarenta y cincuenta del siglo pasado, poblados como Carmona, Matina u Hojancha, eran considerados y llamados "barrios que pertenecían a Mansión" (Batista, 2018), en clara referencia a la dependencia que tenían del comercio y la vida social de esa comunidad. Incluso, afirma que a mediados del siglo $\mathrm{XX}$ se trató de convertir a Mansión en cantón, solicitud que fue denegada por, según comenta, estar esta comunidad muy cerca de Nicoya.

Se recurre en ocasiones a la hiperbolización de ese aspecto comercial de Mansión, y según afirma Laureano Ramos, algunas de las tiendas que existían en la comunidad rivalizaban en tamaño y en variedad de artículos con comercios como La Gloria, la legendaria tienda de departamentos de San José, que funcionó como un referente a nivel nacional antes de la aparición de los mega centros comerciales, a finales del siglo XX. Otro ejemplo que connota abundancia y ajetreo es también el caso del alto consumo de carne que existía en la comunidad. Según uno de los informantes, su padre tenía una carnicería, y "para un 23 de diciembre se mataron once chanchos, en la carnicería de nosotros nada más. A la 1:00 de la tarde no había carne, un 23 de diciembre, imagínese cómo era eso. Ahora un chancho le dura tres o cuatro días." (Ramos 2018b). Este caso es significativo porque, en Costa Rica, siempre el consumo de carne ha sido un símbolo de estatus entre campesinos pobres, y el hecho que los cerdos sacrificados no fueran suficientes para satisfacer la demanda significa que el mercado de consumo de carne estaba bien consolidado, lo que expresaba, a partir del modo en que Ramos narra, abundancia y poder adquisitivo para los estándares de la época. Los mismo hermanos Ramos afirman, sin embargo, que su familia vivía en la pobreza "porque no tenían tierra propia", y ellos de niños no podían darse "lujos" como consumir en las tiendas, restaurantes, o asistir al cine del lugar. Otro ejemplo de hiperbolización es la descripción que hace otro entrevistado, Manzán Díaz, quien afirma que "de Mansión a Pueblo 
Viejo, en tiempos de cosecha, la ronda a ambos lados de la calle, a lo largo de todo el camino, estaba abarrotada de arroz, frijoles, maíz y otros productos apilados y listos para ser transportados a Puntarenas" (2018).

El centro del poblado es recordado "con una calle estrecha, que venía de Nicoya. Las casas de madera, algunas muy bien presentaditas. Había unas casas como más cerradas y con corredor al frente. La actividad era de mucho movimiento, se veía mucha gente a caballo que bajaban de los cerros, los aledaños, en ese momento la agarraban [a Mansión] como el centro" (Arauz, 2018). Es interesante la conexión que hace Arauz entre Nicoya y Mansión, a nivel logístico, por una calle que hoy en día es mucho menos transitada que la que se usa para comunicar ambos lugares en la actualidad. Es decir, la mención a ese enlace con Nicoya es sugerente en el sentido que ya no existe, al menos a través de la calle en cuestión, y eso denota toda una forma diferente de ver el entorno a mediados del siglo XX.

Al preguntarle al entrevistado qué quiere decir con casas "más cerradas", este se refirió a un tipo de arquitectura diferente a la típica casa de madera guanacasteca, que cuenta con rejillas de ventilación en la parte superior de la pared externa, y que rara vez tiene terraza. Ese tipo de construcción más cerrada, el entrevistado no tardó en atribuirlo a los cubanos, que, según dice, tenían otra forma de construir; también se mencionó la influencia "cartaga", como llaman los guanacastecos a los venidos del Valle Central. Es interesante, a partir de esta acotación, notar que el legado cubano permanecía en el paisaje arquitectónico de las casas de Mansión, aún a mediados del siglo $\mathrm{XX}$.

Los entrevistados, sin excepción, también enfatizan la importancia de Mansión como puerta de entrada, no solo, dicen ellos, a Nicoya, también a otras regiones de la provincia. "Si Mansión se paralizaba, se paralizaba todo Guanacaste, porque era la puerta de entrada y salida", afirma uno de los entrevistados. En esa época, sostienen, había en el pueblo un almacén del Consejo Nacional de la Producción (CNP), en el que se recogía las cosechas, no solo de Mansión, sino de todos los pueblos aledaños, incluido Hojancha, y se embarcaban a Puntarenas. Es decir, a nivel logístico, la comunidad funcionó como una especie de eje y centro de actividad que articulaba una gran parte de Guanacaste con el resto del país, vía Puntarenas.

Rubaldo Batista relata con orgullo que la carretera de Puerto Jesús a Mansión, y que posteriormente continuaba a Nicoya, fue la primera carretera asfaltada de Guanacaste, a mediados 
del siglo pasado. Comenta que mucha gente no sabe eso, porque debido a la falta de mantenimiento, la capa asfáltica fue destruida y de nuevo se convirtió en una calle da grava, pero afirma haberla visto y transitado, por ahí de 1945 (Batista, 2018). A partir de mediados de la década de los sesenta, sin embargo, ese estatus de Mansión fue decayendo rápidamente al abrirse otras vías de comunicación, por tierra, entre Guanacaste y el resto del país, y quedar los puertos de cabotaje, entre ellos puerto Jesús, en desuso, (Marín y Núñez 2011).

Mansión como centro de producción agrícola en el recuento del paisaje

Finalmente, en cuanto a la tercera derivación del paisaje en este trabajo, en este caso, en clara referencia al mismo como jeroglífico social, desde la perspectiva productiva, al consultarle a los entrevistados acerca de lo que recuerdan de la constitución de los terrenos alrededor del caserío, estos no solo resaltan lo que para ellos era una mayor riqueza escénica, sino también una mayor diversidad productiva que la actual. En tal diversidad, casi todos los habitantes explotaban el suelo de forma más variada y provechosa. También hacían un mayor uso, en sus momentos de ocio, de recursos naturales como el río Morote, ya sea como sitio para nadar o bien para pescar peces y camarones.

Arauz afirma que antes de llegar a Mansión, yendo de Nicoya, "siempre se veía cultivos, principalmente de maíz y frijol. Poco arroz. Había tiquizque, yuca y algunos sembraban tabaco. Y había caña. La caña era solo para consumo de trapiches locales. Muy pocas matas de tabaco, para consumo familiar. Todos [los cubanos] fumaban puro; porque en Nicoya fumaban cigarro [cigarrillos procesados], y ellos no, fumaban puro" (Arauz, 2018). Pablo Ramos confirma la diversidad agrícola que existía en Mansión: “había agricultura más que todo, el ganado no era mucho. El clima era menos seco, y existía el CNP, por lo que era más fácil vender lo que se sembraba. Ahora no hay dónde vender. Ahora siembran 90 hectáreas de arroz y tienen que buscar cómo lo venden porque no hay CNP” (Ramos, 2018). Rubaldo Batista, que tiene memorias del mismo camino unos veinte años antes que Arauz y Ramos, afirma que había mucha cobertura boscosa, cultivos de caña, tabaco, maíz y frijoles, y que prácticamente no había terrenos dedicados a la ganadería (Batista, 2018). Todos coinciden en que durante su infancia llovía más, por lo que era más fácil sembrar y cosechar con menores riesgos de sequía que ahora, o bien con menor 
inversión, específicamente ante la poca necesidad de cavar pozos profundos, contrario a lo que sucede hoy en día.

En los tres entrevistados anteriores es interesante notar la descripción de un paisaje que denota mayores relaciones sociales y formas de explotación de la tierra que las que pueden denotar hoy en día los espacios narrados por los informantes. Una vez más, en estas descripciones se sugiere una fuerte presencia del legado de Maceo y los cubanos, aún a mediados del siglo pasado. Esta presencia no solo tiene que ver con el hecho de que aún Mansión era tierra de mayor diversidad agrícola que en la actualidad, sino que algunos de los cultivos mencionados por Arauz y Batista son los mismos que se estipula, en el contrato Lizano-Maceo, que los cubanos cultivarían en la zona: "cacao, caña de azúcar, tabaco y café" (Asamblea Legislativa, 2018). A la vez que el tabaco, un cultivo hoy en día totalmente extinto en Nicoya, claramente representa ese vínculo con Cuba, como bien lo especifica Arauz, que lo recuerda como un producto para consumo local de los descendientes de cubanos; o bien como lo recuerda Batista, como un cultivo de índole comercial que aún en su niñez se procesaba y se enviaba a Puntarenas para su exportación, o bien al centro del país. Hoy en día, tanto en los alrededores de Mansión como en los caminos que conducen al poblado, con excepción de cultivos ocasionales de arroz, los sembradíos narrados por los informantes no existen. Tampoco existen los centros de acopio del CNP, y la ganadería proveniente de Nicoya, con poca inversión de capital y de mano de obra, se ha ido apoderando del espacio que antes ocuparan estos cultivos, al tiempo que se han ido construyendo nuevas formas de relaciones sociales.

\section{Conclusiones}

Conforme pasa el tiempo el legado cubano y de Antonio Maceo en Mansión va quedando en los recuerdos de adultos mayores, y cada vez menos en jóvenes interesados en ser conscientes de los pormenores de los orígenes de su comunidad. Las historias nacionales parecen imponerse sobre las locales, menos útiles para propósitos de cohesión hegemónica de proyectos políticos, económicos y sociales a gran escala. Incluso a nivel provincial, como bien lo advierten los paisajes que se pueden observar hoy en día en los alrededores de Mansión, la unidad de producción ganadera parece haberse impuesto, por diversas razones que obedecen a políticas locales y nacionales, a la pujante diversidad y explotación agrícola que apuntan los entrevistados para este trabajo. 
No se trata de recurrir a la nostálgica idea que dice que todo tiempo pasado fue mejor, pero sí es importante considerar lo valioso del aporte de los entrevistados en cuanto a que, no solo hablan desde una perspectiva que los empodera con conocimiento y propiedad del tema, por encima, en muchos casos, de lo que un historiador profesional pueda recabar por otros medios, sino que se expresan desde una posición que los hace sentirse conocedores de los temas que se les consulta, a la vez que demuestran capacidad de poder emplear naturalmente y sin esfuerzo alguno medios para definir lo que son, su herencia cultural, cómo se imaginan y los modos en que se narran.

Queda demostrada la tesis del paisaje como jeroglífico social, planteada al inicio de este capítulo, en el contexto de la Mansión de mediados del siglo XX. Todos los paisajes recabados en este trabajo, de boca de los informantes, denotaron relaciones sociales entre los diferentes actores, locales, provinciales, nacionales y extranjeros, que por alguna u otra razón aparecen en las entrevistas. Ricas relaciones económicas son palpables en los paisajes aledaños comentados en las conversaciones. Estas relaciones son más variadas, con más actores y con una mayor interacción con el devenir del centro de la comunidad que las observadas hoy en día. Es decir, la producción ganadera actual ni se comercia o almacena en Mansión, ni conduce a las mismas prácticas sociales y de trabajo que los cultivos de antaño. Tampoco sucede con cultivos ocasionales como el arroz, que en mucha menor medida aún existen en la actualidad.

A nivel social, las relaciones dictadas a través de la descripción de paisajes remotos también demuestran un componente muy importante de Mansión, del cual muchos adultos mayores se sienten orgullosos, aunque las generaciones más jóvenes en su gran mayoría ignoran: la importancia logística de Mansión, como puerta de entrada a la parte central de Guanacaste, como centro de reunión y ocio de pueblos aledaños, como una comunidad que, a mediados del siglo XX, era capaz de mantener un cine, algo que, en las circunstancias actuales podría resultar increíble, entre otras situaciones acotadas en el análisis de las entrevistas. Y finalmente, la cuestión identitaria, en el caso de los entrevistados, el verse a sí mismos como parte de ese legado de Maceo y los colonos cubanos, además de los modos distintos en que dimensionan esta situación, algunos en mayor medida que otros.

Finalmente, el uso del paisaje como forma de ver y como forma de recordar, contribuye a diversificar los estudios históricos acerca de Mansión, a través del uso de la teoría crítica acerca del paisaje, al menos la utilizada para este trabajo, como forma de dimensionar una realidad, y, por 
otro lado, la historia local como herramienta para rescatar versiones particulares del pasado que no estén necesariamente ligadas con proyectos mayores. Los elementos dilucidados en este trabajo, se espera, entonces, permitan diversificar el estudio del legado cubano y de Maceo en Mansión, y contribuyan a rescatar otras visiones del pasado, aparte de las que más abundantemente circulan en el ideario histórico de Guanacaste y Costa Rica en general.

\section{Referencias}

Álvarez, A. y E. Barboza (2016). Costa Rica en Antonio Maceo. San José: Editorial Arlekín.

Arauz, C. (2012). Las brisas del Morote. San José.

Arauz, C. (2018). Entrevista con Esteban Barboza. San Isidro de Coronado, San José. 19 de marzo de 2018.

Asamblea Legislativa (2018). Contrato Lizano-Maceo 1891. Servicios documentales. Recuperado en http://www.asamblea.go.cr/sd/Lists/Consultas\%20Biblioteca/DispForm.aspx?ID=1616\& ContentTypeId=0x01006D6BF9436BDE9744B205E77060552A13

Barboza, E. (2014). "El proyecto de sociedad de Antonio Maceo en Nicoya como alternativa a la unidad de producción dela hacienda ganadera: implicaciones filosóficas, económicas y culturales en el contexto de la Guanacaste de finales del siglo XIX". Revista Calibán. 19, p. 3-15.

Barboza, E. (2014b). "Esencialismo versus multiplicidad en la institucionalización identitaria de Guanacaste: algunos problemas y propuestas en torno a la guanacastequidad". Guanacaste vive: la historia de Guanacaste en el marco del desarrollo socio regional 1820-2012.

Batista, R. (2018). Entrevista con Esteban Barboza. Nicoya, Guanacaste. 27 de marzo de 2018.

Burke P. (1996). Formas de hacer historia. Madrid: Alianza. 
Castillo, M. (2016). Contextualización histórica del concepto de paisaje, sus implicaciones filosóficas y científicas. Revista de Filosofía de la Universidad de Costa Rica. 54 (143). 11-24.

Cortés, C. (2003). La invención de Costa Rica. San José: Editorial Costa Rica.

Delgado, U. (1969). Maceo en Costa Rica. San José: Ministerio de Educación Pública.

Díaz, M. (2018). Entrevista con Esteban Barboza. Nicoya, Guanacaste. 25 de junio de 2018.

Dormaels, M. (2011). Patrimonio, patrimonialización e identidad: hacia una hermenéutica del patrimonio. Revista Herencia. 24 (1y2). San José: Universidad de Costa Rica. 7-14.

Edelman, M. (1998). La lógica del latifundio: las grandes propiedades del noroeste de Costa Rica desde finales del siglo XIX. San José: Editorial de la Universidad de Costa Rica.

Geertz, C. (1994). Conocimiento local: ensayos sobre la interpretación de las culturas. Barcelona: Paidós.

Gramsci, A. (1971). The Prison Notebooks. Londres: Elecbooks.

Jiménez, A. (2005). El imposible país de los filósofos. San José: Editorial de la Universidad de Costa Rica.

Kant, I. (1977). Crítica del juicio. México: Espasa-Calpe.

Kohut, H. (1977). The Restoration of the Self. Nueva York: International Universities Press.

Lobo, T. (2010). El año del laberinto. San José: Uruk.

Marín, J. R. Núñez (2016). “El impacto de Antonio Maceo en el contexto guanacasteco 18901940.” Costa Rica en Antonio Maceo. A. Álvarez, E. Barboza (Eds.). San José: Arlekín.

Marín, J. R. Núñez (2011). "El cabotaje guanacasteco: un análisis de sociabilidad” Relecturas de Guanacaste 1821-2010. J. Marín, R. Núñez (Eds.). San José: Alquimia 2000.

Marx, K. (2007). El capital. Madrid: Akal.

Mitchell, W. (2009). "Paisaje imperial”. Katatay. 7, 112-129.

Mitchell, W. (2002). Landscape and Power. Chicago: The University of Chicago Press. 
Molina, I. (2002). Costarricense por dicha. San José: Editorial de la Universidad de Costa Rica.

Portell, H. (1948). “Costa Rica y Cuba en Manuel González Zeledón”. Repertorio Americano. 1058, p. 104-112.

Prado, L. (2006). “Historia local e identidades”. Historia y espacio. 2 (27). 1-13.

Quesada, A. (1995). La formación de la narrativa nacional costarricense. San José: Editorial de la Universidad de Costa Rica.

Ramos, L. (2018b). Entrevista con Esteban Barboza. Nicoya, Guanacaste. 9 de marzo de 2018.

Ramos, P. (2018). Entrevista con Esteban Barboza. Nicoya, Guanacaste. 9 de marzo de 2018.

Reyes, E. y A. Matos-Guerra. "Con ternura de hijo quiere el cubano bueno a Costa Rica". Temas de Nuestra América: Revista de Estudios Latinoamericanos. 33, 191-213.

Sequeira, W. (1985). La hacienda ganadera en Guanacaste: aspectos económicos y sociales, 1850-1900. San José: Editorial de la Universidad Estatal a Distancia.

Serrano, P. (2009). "La historia local en América Latina: tendencias, corrientes y perspectivas en el siglo XX". Historelo. 1(1), 8-32.

Sloterdijk, P. (2007). En el mundo interior del capital. Madrid: Siruela. UNESCO (2014). Patrimonio mundial. Recuperado en http://www.unesco.org/new/es/mexico/work-areas/culture/world-heritage/

Vargas, A. (2001). Idearium Maceísta. San José: Editorial Juricentro.

Zubelzu, S. y F. Allende (2015). El concepto de paisaje y sus elementos constituyentes: requisitos para la adecuada gestión del recurso y adaptación de los instrumentos legales en España. Cuadernos de geografía. 24 (1), 29-42.

Zuluaga, F. (2006). "Unas gotas: reflexiones sobre la historia local”. Historia y espacio. 27, $1-11$. 